DEPARTMENT OF MANAGEMENT

\title{
No place to hide: \\ When shame causes proselfs to cooperate
}

Carolyn H. Declerck, Christophe Boone \& Toko Kiyonari

\author{
UNIVERSITY OF ANTWERP \\ Faculty of Applied Economics

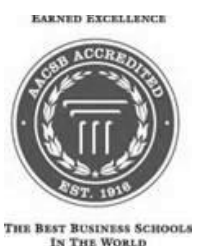 \\ Stadscampus \\ Prinsstraat 13, B.226 \\ BE-2000 Antwerpen \\ Tel. +32 (0)3 2654032 \\ Fax +32 (0)3 2654799 \\ http://www.ua.ac.be/tew
}




\title{
FACULTY OF APPLIED ECONOMICS
}

\author{
DEPARTMENT OF MANAGEMENT \\ No place to hide: \\ When shame causes proselfs to cooperate \\ Carolyn H. Declerck, Christophe Boone \& Toko Kiyonari
}

RESEARCH PAPER 2011-018

NOVEMBER 2011
University of Antwerp, City Campus, Prinsstraat 13, B-2000 Antwerp, Belgium Research Administration - room B.226 phone: (32) 32654032 fax: (32) 32654799
e-mail: joeri.nys@ua.ac.be

The papers can be also found at our website: www.ua.ac.be/tew (research > working papers) \& www.repec.org/ (Research papers in economics - REPEC)

$D / 2011 / 1169 / 018$ 


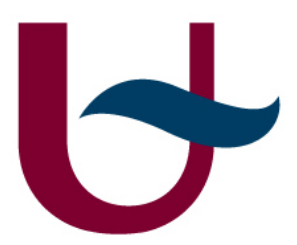

No place to hide: When shame causes proselfs to cooperate

\author{
Carolyn, H. Declerck , ${ }^{*}$ Christophe Boone,${ }^{*}$ and Toko Kiyonari
}

* University of Antwerp, Faculty of Applied Economics, Prinsstraat 13, 2000 Antwerp, Belgium

Corresponding author: Carolyn H. Declerck

carolyn.declerck@ua.ac.be 


\title{
No place to hide: when shame causes proselfs to cooperate.
}

\begin{abstract}
Shame is often considered a moral emotion with action tendencies shaped by natural selection to elicit socially beneficial behavior. Yet, unlike guilt or other social emotions, prior experimental studies do not indicate that incidental shame boosts prosocial behavior. Based on the affect as information theory, we hypothesize that incidental feelings of shame increase cooperative behavior, but only for self-interested individuals, and only in situations where shame is relevant with regards to its action tendency of avoiding reputation losses. To test this hypothesis, cooperation levels are compared between a classic prisoner's dilemma (where "defect" may result from multiple motives) and a sequential prisoner's dilemma (where "defect" is the result of intentional greediness). The results indicate that, as hypothesized, proself individuals cooperate more following incidental shame, but only in a sequential prisoner's dilemma. Hence ashamed proselfs become inclined to cooperate when they believe they have no way to hide their greediness, and not necessarily because they want to make up for earlier wrong-doing.
\end{abstract}

Key words: shame, cooperation, moral emotions, prisoner's dilemma, affect as information, social value orientation 


\section{Introduction}

Emotions have been studied extensively in social interaction to understand why people cooperate under uncertainty, or help others when there are no apparent benefits involved, and why they sometimes even do so at a cost to themselves. Shaped by natural selection, social or moral emotions, such as guilt, pride and shame, may play an important role in maintaining cooperation, as they underwrite adherence to social norms and thereby facilitate group functions (Bowles \& Gintis, 2002). Moral emotions motivate cooperative decision-making by eliciting action tendencies that benefit interpersonal relationships, and bypass the explicit cognitive deliberation process that analyzes cost/benefit ratios. Prosocial behavior elicited by moral emotions have been shown to be an effective way to remove or avoid the negative feelings associated with norm transgression (Baumeister, Stilwell, \& Heatherton, 1994; Cialdini, Darby, \& Vincent, 1973; Frank, 1988; Haidt, 2003). This study further explores specifically why and when the emotion of shame affects cooperative decision making in social dilemmas.

Shame refers to the "feeling of discomfort at having done something wrong not only by one's own norms, but also in the eyes of those whose opinions matter to you" (Bowles \& Gintis, 2002, p. 3). Shame differs from guilt because the latter can be felt without others knowing about the violation. Shame occurs from the overt act or the private thought of publically exposing one-self (Tangney, Stuewig, \& Mashek, 2007). Darwin (1872) already alluded to the public aspect of shame when he described how blushing is caused by "thinking of others thinking of us." Other authors have considered shame as one of the most genuine self-referential emotions by which the self is evaluated according to feedback from the social environment (Zinck, 2008). An fMRI study confirms this: contrasting brain activity of shame versus guilt during evaluative processes revealed that shame is a neurologically more 
complex emotion that recruits additional neural activity in brain regions associated with theory of mind and self-referential thinking (Takahashi et al., 2004).

Shame and guilt are both elicited by norm transgressions, but when evaluating the fact "I did something bad," guilt feelings would focus on the something and how to repair it, while shame would emphasize the $I$ and where to hide or how to restore it (Tangney et al., 2007). Therefore, the action tendency of shame and guilt also differ. Guilt is other-directed and elicits the action tendency of repairing damage done to others. Shame on the other hand is self-directed and appraised as "losing face" or "being the center of negative attention" (de Hooge, Zeelenberg, \& Breugelmans, 2007). At least two different action tendencies following shame have been described: (1) either to hide and withdraw from further social interaction to avoid further public condemnation (Tangney et al., 2007), or (2) to repair the damage done to one's self-image and undo the shame situation (de Hooge et al. 2008; Frijda, Kuipers, \& Ter Schure, 1989). How we think others will view our amends is utterly important when we are ashamed, and there is some field evidence that the relation between shame and reparation attitude is mediated by a desire to improve one's reputation (Brown et al., 2008). If shame spurs prosocial behavior, it is likely related to the second action tendency and meant to restore a positive public image.

There are two fundamental ways by which emotions can affect decision making (Lerner \& Keltner, 2000). First, integral emotional influences occur when the emotioncausing event is related to the goal pursuit. If restoring one's reputation is the goal, feeling ashamed of having been caught violating an important social norm may boost prosocial behavior. Such integral effect on cooperation has been illustrated several times in repeated experimental social dilemmas for the emotion of guilt. When guilt is experienced after initially defecting, cooperative decisions increase in subsequent rounds (Ketelaar \& Au, 2003; Miettinen \& Suetens, 2008). For shame, the integral affective influence is often presumed. In 
the classic field study, "a fine is a price," the punctuality of parents picking up their children from daycare dropped drastically when a fine was imposed. Apparently, parents gladly paid the fine to rid themselves of shame, but at the same time reduced their efforts to abide by day care hours. Under the normal, no-fine condition, the anticipated shame of being late is believed to influence parents to respect the norm of being on time (Gneezy \& Rustichini, 2000).

Second, incidental emotional influences occur when the emotion-causing event is unrelated to the decision making process. An abundance of studies has revealed that moods caused by watching movies, sunny weather, or stressful exams, may infuse judgment in unrelated topics (Forgas, 1995). In addition, if the emotion (like shame) serves as an evolutionary relevant cue (losing face and ostracism), it may become over-applied and misattributed to an unrelated situation. This incidental effect of shame would then be similar to the finding that stylized painted eyespots can influence prosocial behavior in a one-shot dictator game (Haley \& Fessler, 2005) or in anonymous donations to charity (e.g., Bateson, Nettle, \& Roberts, 2006). The idea of being watched is misattributed to the painted eyespots.

So far only a few studies have addressed the incidental influences of social emotions on cooperative behavior. An experiment by Nelissen, Dijker, and de Vries (2006) showed that experimentally induced guilt increased cooperative decisions in a simultaneously played prisoner's dilemma, but that this was moderated by individual differences in social value orientation. This personality trait has been widely studied in social psychology and typifies social preferences and the different strategies people use to solve social dilemmas. An individual with a prosocial value orientation typically prefers the collectively beneficial outcome, while an individual with a proself orientation tends to maximize self interest (Van Lange, 2000). When Nelissen et al. examined the moderating effect of social value orientation on the relation between guilt and cooperation, they found that only proself 
individuals, who usually defect (play Nash) in a simultaneously played social dilemma, responded to incidental feelings of guilt by cooperating more. Hence they over-applied the reparative action tendency of guilt to a situation in which it is not in their self-interest to cooperate. Prosocials, who readily cooperate in all types of social dilemmas, were not additionally affected by induced feelings of guilt. Later de Hooge et al. (2007) replicated the experiment comparing guilt and shame, but they were unable to find any incidental influences of shame on cooperative behavior. In a follow up study (de Hooge, Breugelmans, \& Zeelenberg, 2008) they specifically compared the integral and incidental effect of shame on prosocial decision-making, hypothesizing that shame would only motivate cooperative behavior when it was integral, and therefore naturally relevant to the decision at hand. In a series of experiments, participants played a give-some dilemma game with a partner who either knew about the participant's preceding shameful behavior (the integral shame condition), or did not know about it (the incidental shame condition). Their results indicated that proselfs became more cooperative in response to integral, but not incidental influences of shame. Presumably, shame was not informative and hence not influential with regard to decision-making in their experimental paradigm.

The purpose of the current study is to further investigate if and when incidental shame can boost prosocial behavior. Based on the affect-as-information model (Schwartz \& Clore, 1983), we propose that the effect of incidental shame on cooperative behavior depends on a person's social value orientation and on the extent that feelings of shame can serve as relevant information with regards to its action tendency (i.e., preventing further reputation losses). We build on the study of de Hooge et al. (2008) and propose that incidental shame can be relevant to cooperative decision-making when the apparent intentions of the decisionmaker are visible. In that case, individuals who are concerned about not appearing selfish in public will be influenced by incidental feelings of shame in order to hide greediness. Before 
presenting the details of the experiment, we elaborate further on the various conceptual aspects of this hypothesis: the affect as information model, social value orientation, and the visibility of the intent of decision-making.

\section{Affect-as-information model}

Affect infusion occurs when the forces that normally lead to decisions are overridden by incidental emotions. This typically happens during heuristic processing, when affective states induced by emotions in one context are used as information to influence decisionmaking in a different context. The mechanism for this infusion is summarized by the affectas-information model (Clore 1994; Clore, Schwartz, \& Conway, 1994; Schwartz \& Clore, 1983; Slovic et al., 2004). According to this theory, people rely on present feelings to make complex judgments, as long as the experienced feeling is perceived to be relevant for the decision. They ask themselves: "how do I feel about this decision?" and then let themselves be guided by that feeling. Translating this to shame, the bad feelings from incidental shame informs the decision maker heuristically about consequences of (non)-cooperation, and bias the decision to avoid possible reputation losses. Because people do not like being labeled greedy, their decision under the influence of shame becomes less selfish and more cooperative, at least when the intent of greediness would have been clear otherwise.

The affect-as-information model can only account for the presumed effect of incidental shame on cooperative behavior if the following three requirements are met. First, the information has to be processed subconsciously. Conscious knowledge of the source of an incidental emotion tends to remove its infusion potential (Forgas, 1995). Once people contemplate that the shame they experience is unrelated to the decision they need to make, they are unlikely to be influenced by it. Therefore, incidental shame can only serve as a 
heuristic in an anonymous one-shot interaction. If the decision is associated with real reputation benefits or losses, cognitive deliberation will override heuristic processing, and the effect of incidental shame will vanish. Second, the decision maker has to care about her/his cooperative reputation. And third, a non-cooperative decision has to be clearly perceived as an intentional norm transgression. In order for these latter two conditions to be met, we need to consider (1) the moderating effects of a person's social value orientation and (2) the decision context.

\section{Social value orientation}

The personality construct social value orientation (SVO) captures the idea that there are stable individual differences in cooperative strategies among people that have opposing social preferences. People can be classified according to a number of orientations, of which the proself and prosocial ones are probably the most commonly studied (Van Lange 2000). Proselfs view disagreements or social dilemmas as win-lose situations and will strive to fulfill their own goals (individualists), or maximize their own gain relative to others' gains (competitors). Prosocials seek win-win situations and strive for equality in outcome. In dilemma situations, they are naturally inclined to cooperate, even in one-shot interactions. However, they do not remain unconditionally cooperative but are behavioral reciprocators who stop cooperating when encountering a non-cooperative partner (De Cremer \& Van Lange, 2001, Van Lange \& Semin-Goossens, 1998). Proselfs in contrast expect others to also have a proself orientation and are therefore unlikely to initiate cooperation when the likelihood of remuneration is small (Van Lange, 1992). An abundance of research has shown that these social value orientations are temporally stable, present at an early age in a child's 
temperament, and that they have much predictive value with respect to cooperative motives, strategies, and choice behavior (reviewed in Bogaert et al., 2008).

In line with previous reports on the prosocial effect of moral emotions (Ketelaar \& Au, 2003; Nelissen et al., 2007; de Hooge et al., 2007, de Hooge et al., 2008), we hypothesize that social value orientation moderates the positive effect of shame on cooperation, and that this will be especially so for proself individuals, as will be explained below.

Proselfs cooperate strategically when it is in their best interest to do so, and will therefore respond very positively to cooperative incentives (Boone et al., 2010). Reputation is a well-known cooperative incentive (Wedekind and Milinski, 2000) and a major reason for proselfs to cooperate. In two experiments, Simpson and Willer (2008) showed that proselfs acted cooperatively when reputational incentives were at stake, and defected when opportunities for reputation gains or indirect reciprocity were absent. In contrast, prosocials, were significantly more likely to cooperate in all conditions, regardless of reputation incentives. In addition, proselfs were more likely than prosocials to discount other's cooperative acts when they occurred in public situations that allowed for reputation gains. The latter finding reveals that proselfs are very much aware of the strategic nature of their own cooperative behavior. Because shame elicits reputation concerns (maintaining a positive image), the negative affect will enter their utility function and heuristically bias decisionmaking towards avoiding reputation losses. Thus, we predict that shame will induce proselfs to cooperate when they cannot cover up a selfish decision. Consistent with the affect-asinformation theory, we expect incidental shame to be misattributed to anonymous interactions, where proselfs usually do not cooperate. When social interactions are public, proselfs naturally become very generous in order to boost their reputation and gain social standing (Simpson \& Willer, 2008). The relevance of shame as information is that it subconsciously 
activates schemata of losing face in public. Thereby, shame influences decision-making of proselfs so that an anonymous exchange is treated as if it were public.

Prosocials, in contrasts have internalized the cooperative norm and cooperation is a chronically activated goal. For them, losing face is less an issue in a social dilemma because their cooperative behavior depends more on the expectation of reciprocity (Bogaert et al., 2008) and less on the presence of reputational losses or benefits (Simpson \& Willer, 2008). Of course prosocials care about not losing face, but this concern is not directly related to their cooperative behavior. Cooperation is their default strategy, and defect is usually a response to an non- cooperative partner and hence not a shameful act that they associate with losing face in public. Therefore, it is not immediately clear how the incidental affective state of shame will inform prosocials' decision-making. With respect to shame's action tendency of restoring a positive image (de Hooge et al., 2008), we expect no influence on cooperative behavior. However, with respect to shame's action tendency of withdrawing (Tangney et al., 2007), it is also possible that the affective state of shame might interfere with prosocials' normal perceptual judgment of a situation, which may or may not hamper their intrinsic cooperative decisions.

\section{The prisoner's dilemma as decision context}

The affect-as-information model further specifies that the incidental emotion should be relevant with respect to the outcome of the decision. Incidental shame is only relevant to a decision-maker in situations where reputation losses are possible. To manipulate the idea of reputation losses, we compare the effect of shame on cooperation in two versions of a prisoners' dilemma game (PD). 
The pay-off structure for the actual PD game used in this experiment is shown in Figure 1. In the classical PD, two players choose between a mutually beneficial, but risky cooperative option, (L) or a more lucrative but collectively deficient defect option (S).

Figure 1: Pay-off matrices for the prisoner's dilemma.

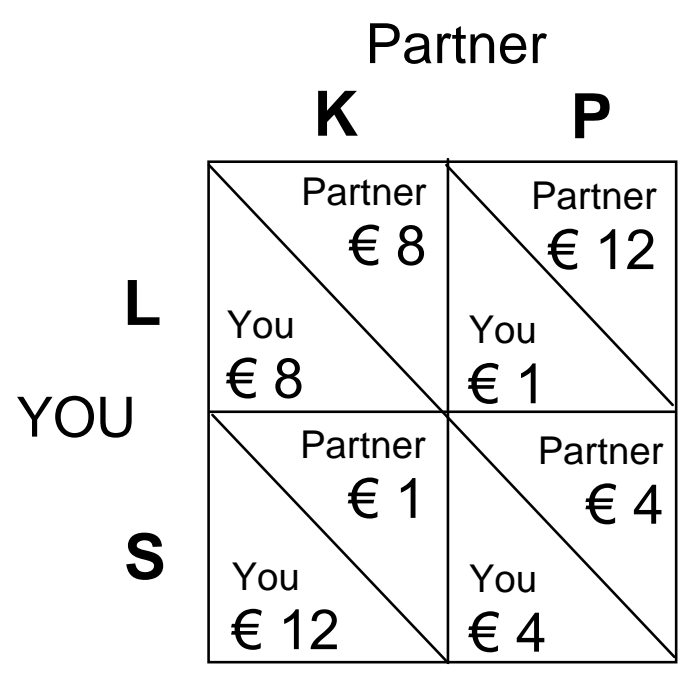

When both players make their decision simultaneously, defect is the dominant response, because, irrespective of the strategy of the other person, a rational decision-maker can always increase his or her pay-off by choosing to defect. The motives to defect, however, are mixed, and may depend on a person's intrinsic cooperative preferences (Bogaert et al., 2008; Kollock, 1998; Pruitt \& Kimmel, 1977). While a rational, self-interested person defects out of greed, a rational cooperative person may also defect out of fear of betrayal by an anonymous alter. Because the simultaneous game is played not knowing alter's decision, a non-cooperative decision can always be considered a cautious decision. Because cautious acts are not something to be ashamed off, we expect that shame - in as much that it causes subsequent reputation concerns - will not have a positive effect on cooperative behavior in the simultaneously played PD game. Uncooperative people (proselfs) can always hide their 
underlying greedy motive beneath the caution dictated by the game. This is a possible reason why shame was not found to elicit cooperative behavior of proselfs in the study by de Hooge et al. (2007).

When, on the other hand, the PD is played sequentially, the decision of the first player is revealed to the second player before she makes her decision. This removes the risk of betrayal for the second player, whose decision now becomes one of reciprocation. Without the induction of shame, we expect the behavior of prosocials and proselfs to diverge especially in the sequential PD. Because prosocials are especially sensitive to trust (Boone et al., 2010), we expect that as a second player they will naturally increase their level of cooperation because there is no longer a risk of betrayal. Second player proselfs, on the other hand, are expected to exploit the cooperative behavior of a first player.

The affective state of shame, however, may become relevant for the second-mover in the sequential PD game. Not reciprocating a cooperative offer hurts the first player and is a visible sign of intentional greed. Being greedy does not fit with the cooperative social norm, and a greedy person may not be liked by others. Shame may trigger the idea of social disapproval when one's greedy intentions are revealed. In this case we believe that shame may be especially relevant to the outcome of a decision for a proself individual who is naturally inclined to defect. Prosocials, on the other hand, are expected to naturally cooperate as a second mover in a sequential PD, hence they are less likely to link shame with revealing greedy intentions.

To summarize the intent of the study, we compare the effect of shame on cooperation in a simultaneous and sequential one-shot prisoner's dilemma game (referred to as simPD and seqPD from here on). The simPD and seqPD differ in two respects: first, the simPD imposes a risk of betrayal for both players, while the seqPD gives the second person the choice to either reciprocate or betray the first person. We expect that this difference between 
the two games will lead prosocials to increase, and proselfs to decrease their level of cooperation in the seqPD relative to the simPD (see also Simpson 2004). Second, the seqPD reveals the (greedy) intent of decision-making, while the simPD allows hiding one's non cooperative motives. Accordingly, the affect as information theory predicts that, only in the seqPD, reputation concern associated with shame will enter the decision-making process and reduce non-cooperative decisions. In the simPD, social reputation is not at stake. Shame loses its saliency and is not expected to influence cooperative behavior. We further expect that, due to the more calculative nature of proselfs and their greater concern for reputation-losses associated with non-cooperation, these different effects of shame in both games will apply especially, or only, for them.

\section{Materials and methods}

Design

The experiment has a $2 \mathrm{X} 2 \mathrm{X} 2$ design with type of game as within factor (simPD vs. seqPD), and emotion induction (shame versus control) and SVO (prosocial versus proself) as between factors. The dependent variable is a bivariate indicating whether the participant cooperates or defects.

\section{Population and setting}

The experiment was conducted at the University in June 2008. Participants consisted of 117 students ( 51 males, 66 females, average age $=21$ years, S.D. $=4$ years). They were recruited from different departments via web mail and signed up for one of 3 sessions (with a 
minimum of 36 and a maximum of 44 participants per session). Full anonymity was guaranteed at all times, and monetary incentives were emphasized. Note that anonymity was necessary to test if the induced emotion of shame serves as information for subsequent decision-making (see introduction). Public interactions by themselves would already be a sufficient trigger for cooperation for proself individuals (Simpson \& Willer, 2008) and overwhelm any effect of shame.

\section{Procedures}

Participants in each session were randomly assigned to one of four computer rooms. They read and signed a consent form which told them they would participate in a study conducted by several researchers in the department of Applied Economics. Therefore the study would comprise three parts, including a (1) personality assessment, a (2) memory test, and (3) an interactive economic game. To avoid making the real purpose of the experiment transparent, participants were not told specifically that the various parts of the study were in any way related to one another. To guarantee anonymity, participants were told that no real names would be used in this experiment. Instead, they were asked to compose their own personal ID code ${ }^{1}$ which they were to use throughout all parts of the experiment.

The personality questionnaire was filled in first. SVO was assessed using the nineitem, triple dominance decomposed measure, which distinguishes between a cooperative, individualistic, and competitive orientation. Respondents are classified into one of these three orientations if they make six out of nine choices consistent with one orientation (e.g., Van Lange et al., 1997). The cooperative choices correspond to the prosocial orientation.

\footnotetext{
${ }^{1}$ The personal ID codes consisted of a string of letters and digits composed of their birth order, number of siblings, initials of their mother's first name and maiden name, their mother's birthday (DDMM), and the zip code of their home address.
} 
Following standard practice the individualistic and competitive orientations are combined to form the proself orientation. Many researchers have confirmed that the reliability and validity of the nine item decomposed measure are adequate. Test - retest coefficients range from 60 to $75 \%$ (Bogaert et al., 2008; Van Lange, 2000). The construct validity has been described in detail elsewhere (see Au \& Kwong, 2004; Bogaert et al., 2008).

Next the memory test was conducted, which consisted of both a short-term and a long-term task. The short-term task was a digit span test which was carried out on a computer and lasted about 5 minutes. The purpose of this task was to establish a mental link between this task and the next task, which we named a long-term memory task and was in fact the emotion induction for the intended experiment. In the long-term memory task, participants were asked to write an essay about a true event, including as much detail as they could possibly remember. In the shame condition, the topic of the essay was to describe one or more recent incidences that made them feel very much ashamed. In the control condition, the topic was to describe a recent, ordinary day. Participants were given 15 minutes to write the essay. During this entire time, they were not allowed to converse with each other. An experimenter who was blind to the purpose of the experiment supervised the procedure and stayed in the room the entire time. This emotion-induction procedure is the same as the one applied by Nelissen et al. (2007).

Prior to starting the interactive economic games, participants had written their personal ID codes on paper stubs which had been collected. The instructions of the games explained that all participants were to make a number of decisions for which real money could be earned. For each decision, they were pre-matched with a different partner in another room, and they would never find out who this was. Matching occurred on the basis of the IDstubs that were collected. The outcome of the decision depended on their decision as well as on the decision of their matched partner. To ensure that all participants adequately understood 
the monetary pay-offs of the games, the instructions also included 8 questions that had to be answered correctly before continuing with the actual experiment. The answers were checked by the experimenter.

The actual decisions were made with paper and pencil in answer booklets. Each subject played the two games consecutively with pay-offs as shown in Figure $1 .^{2}$ For the simPD, actual pay-offs were computed based on partner matching. In the seqPD, we were only interested in how the participant (the second player) reciprocates a cooperative decision. Therefore we did not rely on partner matching for this part of the experiment, but instead provided each participant with a pre-determined decision (first player always cooperates), letting the participant believe that this was the decision made by their partner (see Ketelaar \& $\mathrm{Au}, 2003$, for a similar procedure).

The simPD was always played before the seqPD, and no feedback about the partner's decision in simPD was given before playing the seqPD. During the time between games (10 minutes), participants were asked to reread and edit their essay. In this way, both games were primed equally by the emotions induced through writing the essay.

When both games were concluded, participants filled in a post-experimental questionnaire. They were paid in truth their actual earnings ${ }^{3}$ for the experiment. Debriefing occurred by sending each participant an e-mail referring them to a website with a full description of the intent, procedures, and results of the experiment.

\section{Results}

\footnotetext{
${ }^{2}$ During the experiments, participants played an additional coordination game. The pay-off structure in this game does not offer an incentive to defect. The coordination game was added for the purpose of testing a hypothesis that is unrelated to the present study and will be reported elsewhere. The order of the coordination game and the simultaneous prisoner's dilemma were alternated and counterbalanced.

${ }^{3}$ Participants earned anywhere between 18 and 30 euros for a one-and-a-half hour experiment.
} 


\section{Emotion induction}

The shame condition included 59 participants, the control condition 58. To check the adequacy of the shame manipulation, two judges independently read the essays. Following Nelissen et al. (2007), the essays were evaluated on the strength of the described emotion, the level of detail, and the recentness of the shameful event(s). These corresponded to the three criteria that were mentioned in the instructions on how to write the essay. In the control condition, neither judge reported any description of shameful events. In the shame condition, both judges rated all the essays as having anywhere from a "moderate" to "very intense" level of shame. All essays were rated as having sufficient detail. Six essays described childhood events. However, we decided not to exclude these essays because of their high level of detail and because the authors of these particular essays explicitly mentioned that they still felt ashamed today thinking back to the event.

\section{Descriptive statistics}

Fifteen subjects could not be classified as prosocial or proself, and are therefore omitted from further analyses. The proportion of cooperative/defect decisions did not vary between the two types of games $\left(\chi^{2} 1,204=1.3, \mathrm{p}<.26\right)$. Neither did it vary between the shame and the control condition $\left(\chi_{1,204}^{2}=1.2, \mathrm{p}<.28\right)$. As expected, cooperation differed significantly between prosocials and proselfs $\left(\chi_{1,204}^{2}=20.1, \mathrm{p}<.001\right)$. Figures $2 \mathrm{~A}$ and $2 \mathrm{~B}$ report the percent cooperation of prosocials and proself with and without shame induction in the simPD and seqPD, respectively. Visual inspection of Figure 2 also reveals that, in the control condition (dark bars in Figures 2A and 2B), prosocials and proselfs adapt their 
behavior to the seqPD in opposing ways: as expected, prosocials increase and proselfs decrease their level of cooperation.

Figure 2 : Percent cooperative decisions made by prosocials and proselfs in the simPD (figure $2 A$ ) and the seqPD (figure $2 B$ ). Error bars depict standard errors of percentages.

\section{$2 A$}

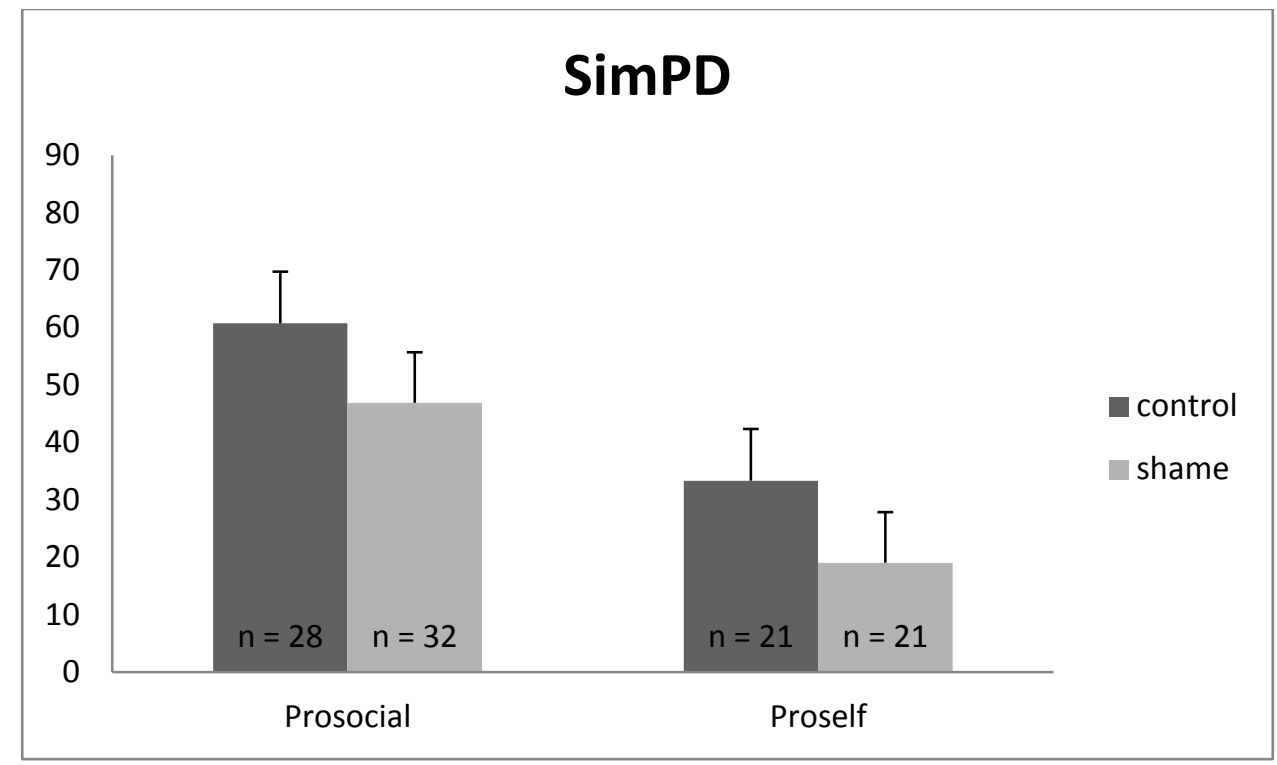

$2 B$

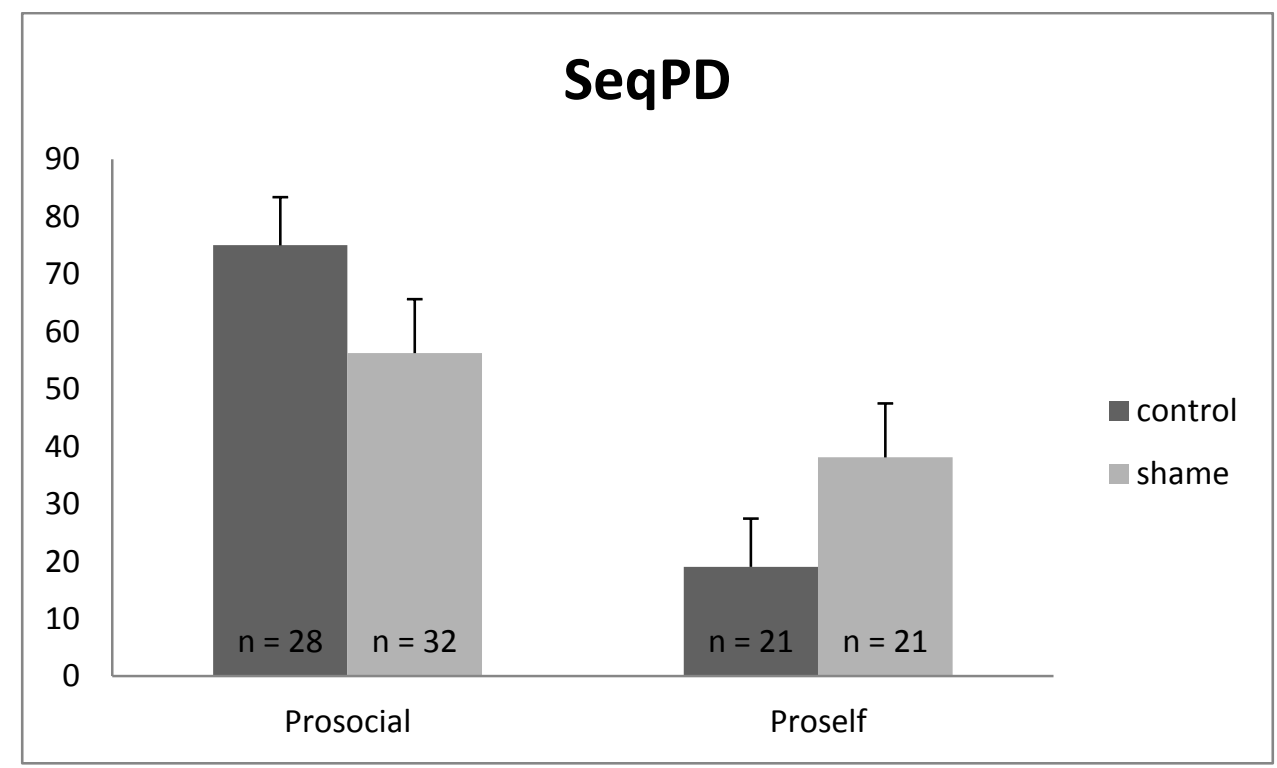




\section{Tests of hypotheses}

The main hypothesis of this study predicts that the effect of shame on cooperation depends on both SVO and the type of game. To test for this three-way interaction, we perform logistic regressions separately for the simPD and the seqPD $(n=102,42$ proselfs, and 60 prosocials). Cooperation is the dependent variable (cooperation $=1$; defect $=0$ ), and SVO $($ prosocial $=1 ;$ proself $=0)$ and emotion condition $($ shame $=1 ;$ control $=0)$ are the independent variables. Age and sex are always added as control variables, because previous studies have indicated that they may significantly impact cooperative behavior (for age, see Van Lange et al.,1997; for sex, see Van Vugt et al., 2007). First we estimated models with the main effects of SVO and emotion condition only. Subsequently, the interaction term of shame and SVO was added to test whether SVO moderates the effect of shame (see Table 1). Finally we compare the B-values of the shame*SVO interaction terms.

In both games, there is again a main effect of SVO, with prosocials cooperating significantly more than proselfs $\left(\mathrm{B}=1.3\right.$, S.E. $=.46, \mathrm{p}<.002^{4}$, for the simPD (see model 1$)$; $\mathrm{B}=1.57$, S.E. $=.45, \mathrm{p}<.001$, for the seqPD $($ model 3$))$. Shame induction, on the other hand, proves to have no main effect in either game $(\mathrm{B}=-.62$, S.E. $=.43, \mathrm{p}<.074$ for the simPD $($ model 1$) ; \mathrm{B}=-.036$, S.E. $=.44, \mathrm{p}<.46$, for the seqPD $($ model 3$))$.

The interaction between shame and SVO is not significant in the $\operatorname{simPD}(\mathrm{B}=.083$, S.E. $=.91, \mathrm{p}<.46($ model 2$))$. In this game, $60.7 \%$ of the prosocials cooperated in the control condition and $46.9 \%$ in the shame condition $\left(\chi^{2} 1,60=1.1, \mathrm{p}<.21\right)$. These percentages amount to $33.3 \%$ and $19.1 \%$ for proselfs, respectively $\left(\chi^{2} 1,42=1.1, \mathrm{p}<.24\right)$. (See also Figure 2A).

\footnotetext{
${ }^{4}$ Because we are testing a specific hypothesis, all $\mathrm{p}$ values assessed from Table 1 and Figure 2 are one-tailed.
} 
However, as predicted, the interaction between shame and SVO is significant in the seqPD $(B=-2.3$, S.E. $=.98, p<.01($ model 4$))$. While prosocials slightly decrease their cooperation levels from $75 \%$ in the control condition to $56.3 \%$ in the shame condition $\left(\chi^{2} 1\right.$, $60=2.3, \mathrm{p}<.11$ ), proselfs nearly double their cooperation levels from $19.1 \%$ in the control to $38.1 \%$ in the shame condition $\left(\chi^{2} 1,42=1.9, \mathrm{p}<.15\right)$. (See also Figure $\left.2 \mathrm{~B}\right)$.

Table 1. Logistic regression coefficients with cooperation as dependent variable (Standard error in parantheses). Cooperation, male, shame, and prosocial are coded 1, zero otherwise.

$*=\mathrm{p}<.05 * *=\mathrm{p}<.01$, one-tailed

\section{SimPD}

Model 1

Model 2

Model 3 SeqPD

\begin{tabular}{|c|c|c|c|c|}
\hline & Model 1 & Model 2 & Model 3 & Model 4 \\
\hline Age & $\begin{array}{l}015 \\
(.051)\end{array}$ & $\begin{array}{l}.015 \\
(.052)\end{array}$ & $\begin{array}{l}.11 \\
(.070)\end{array}$ & $\begin{array}{l}.15^{*} \\
(.076)\end{array}$ \\
\hline Sex & $\begin{array}{l}-.62 \\
(.44)\end{array}$ & $\begin{array}{l}-.62 \\
(.45)\end{array}$ & $\begin{array}{l}-.54 \\
(.45)\end{array}$ & $\begin{array}{l}-.74 \\
(.48)\end{array}$ \\
\hline Shame & $\begin{array}{l}-.62 \\
(.43)\end{array}$ & $\begin{array}{l}-.68 \\
(.74)\end{array}$ & $\begin{array}{r}-.036 \\
(.44)\end{array}$ & $\begin{array}{l}1.4^{*} \\
(.77)\end{array}$ \\
\hline svo & $\begin{array}{l}1.3^{* *} \\
(.46)\end{array}$ & $\begin{array}{l}1.3 * \\
(.62)\end{array}$ & $\begin{array}{l}1.57^{* *} \\
(.45)\end{array}$ & $\begin{array}{l}2.9^{* *} \\
(.78)\end{array}$ \\
\hline Shame*SVO & & $\begin{array}{l}.083 \\
(.91)\end{array}$ & & $\begin{array}{l}-2.3 * * \\
(.98)\end{array}$ \\
\hline Constant & $\begin{array}{l}-.85 \\
(1.2)\end{array}$ & $\begin{array}{l}-.83 \\
(1.2)\end{array}$ & $\begin{array}{l}-3.1^{*} \\
(1.5)\end{array}$ & $\begin{array}{l}-4.5 * * \\
(1.8)\end{array}$ \\
\hline $\mathbf{N}$ & 102 & 102 & 102 & 102 \\
\hline Log likelihood & -63.5 & -63.5 & -61.9 & -59.0 \\
\hline
\end{tabular}


In addition, the B-values for the shame*SVO interaction differ significantly between the simPD and seqPD $\left(\chi_{1,102}^{2}=3.3, \mathrm{p}<.034\right)$, confirming the three-way interaction between the effects of SVO, shame, and game type on cooperation.

\section{Discussion}

The results of this study indicate that a positive effect of incidental shame on cooperation only appears in a situation where the intention to be greedy is clearly visible, and only for people who are especially concerned about losing face when they do not appear cooperative in public. Specifically, the results indicate that in a simultaneously played PD game-context where shame is less salient because a non-cooperative decision can always be considered a cautious decision, experimentally induced shame does not enhance cooperative behavior. Only in the sequentially played PD where a non-cooperative reciprocation is clearly an indication of socially disapproved greed does shame induction prompt proself individuals to become more cooperative. As an explanatory mechanism we propose that incidental shame serves as important reputation information that enters the utility function of proselfs and heuristically biases the decision to avoid the feeling of losing face in public. In the seqPD, the informative feeling of shame leads to cooperation, in the simPD, it does not.

An important assumption we rely on to substantiate that proselfs use emotions as information is that shame triggers a concern for reputation losses, and that this concern affects especially the behavior of proselfs (Simpson \& Willer, 2008). We looked for supporting evidence in the essays in the shame condition. First, we expect that the essays of proselfs would report more reputation concerns than those of prosocials. Second, if only proselfs use affect as information, we expect that reports of "losing face" lead to more cooperation in the seqPD among proselfs compared to prosocials. Two independent judges 
scored the shame essays $(n=59)$ for evidence of "losing face" (reports of losing face $=1,0$ otherwise). They agreed on $75 \%$ of the cases. A third judge scored the $25 \%$ of the essays on which no agreement was reached, and the score for these remaining essays was determined by the $2 / 3$ majority.

There were 21 essays written by proselfs and 32 by prosocials, ${ }^{5}$ and significantly more "losing face" was reported by proselfs $\left(\chi_{1,55}^{2}=5.052, \mathrm{p}=.025\right)$. While losing face did not have a significant main effect on cooperation in the seqPD, it is interesting to note that there was not one cooperating proself who did not report losing face ${ }^{6}$, while a number of proselfs who reported losing face still defected. Hence the idea of "losing face" may be a necessary but not sufficient condition for proselfs to cooperate in the seqPD.

These results complement previous studies that have investigated the role of moral emotions in solving social dilemmas. The prosocial effect of experimentally induced guilt is well-established, and, as with shame, it appears to be moderated by individual differences (Au and Ketelaar, 2003; Nelissen et al., 2007; de Hooge et al., 2007) and by the intent of the decision (Miettinen \& Suetens, 2008). Similarly, integral shame also appears to only affect proself individuals (de Hooge et al., 2008). However, in four studies de Hooge et al. (2008) were unable to reveal incidental influences of shame, not even for proselfs. We believe these results to stem from the fact that their experimental paradigm relied on a simultaneously played social dilemma which offers mixed motives and where defection is not only greedy, but also cautious. This study builds on the premise of de Hooge et al. (2008) that shame arises as a negative evaluation of the self which "activates a focus on others' thoughts about

\footnotetext{
${ }^{5}$ The remaining 6 shame essays were written by unclassified participants.

${ }^{6}$ The interactive effect of loosing face and SVO on cooperation could not be tested because of this fact, yielding a cell with zero frequency. The specific proportions are as follows: For prosocials, 34\% cooperated and reported loosing face, while $22 \%$ cooperated without reporting loosing face; $44 \%$ defected and reported loosing face, while $13 \%$ defected without reporting loosing face. A test of proportion indicates that these differences are not statistically significant, $\chi_{1,32}^{2}=.37, \mathrm{p}<.542$, two-tailed. For proselfs, $38 \%$ cooperated and reported loosing face, while $0 \%$ cooperated without reporting loosing face; $48 \%$ defected and reported loosing face, while $14 \%$ defected without reporting loosing face. Again, a test of proportion indicates that the differences are not significant, but that the test statistic is much larger than for prosocials, $\chi_{1,21}^{2}=2.1, p<.14$, two-tailed.
} 
oneself and on being accepted by the group" (p. 941). Therefore, shame can only motivate prosocial behavior when it is relevant. This can occur through the integral influence of shame (as de Hooge et al. show), or as we have shown, by creating a decision context where the negative aspect of the self becomes apparent because one's (un)cooperative intentions are made clear.

An additional finding of this study for which we had no clear a-priori hypothesis is that shame appeared to consistently (but not significantly) reduce the level of cooperation for prosocials. ${ }^{7}$ A straightforward explanation is that prosocials, who are sensitive to trust and reciprocation, might find betrayal and "being the sucker of a cooperative dilemma" a shameful event. To avoid this shame, they might be naturally inclined to reduce their cooperation level. However, this explanation can only hold for the simPD, where the chance of ending up with the "sucker's payoff" is real. As was mentioned in the introduction, a major difference between the simPD and the seqPD is that the latter removes the risk of betrayal and hence the "sucker's pay-off." Thus increased betrayal aversion cannot be a generalized explanation for the decrease of cooperation observed in shame-induced prosocials.

A very tentative hypothesis that would require extensive further investigation is that heightened caution or betrayal aversion caused by shame creates spill-over effects that interfere with the normative decision-making process of prosocials. Although the focus of this paper was on shame's action tendency of mending a broken reputation, shame can also elicit withdrawal, or freezing behavior to avoid future shameful events (de Hooge et al., 2007; Tangney et al., 2007; Zinck, 2008). For prosocials whose cooperative decisions are driven by trust (Boone et al., 2010) and intuitive reasoning (Haruno \& Frith, 2010), withdrawing from social interaction might imply a reduction in their automatic concern for others. This would not be true for proselfs, who tend to be less sensitive to trust and the possibility of betrayal

\footnotetext{
${ }^{7}$ The negative effect of shame on cooperation for prosocials only (combining the data from both games) is marginally significant (Logistic regression, with cooperation as dependent variable, age and sex as control variables, and shame as dependent variable: $\mathrm{B}=-.72$, S.E. $=.40, \mathrm{p}<.070)$.
} 
(Boone et al., 2020), and whose decisions are not the result of trust versus caution but of calculation and frontal lobe activity (Emonds et al., 2010). We realize this hypothesis is highly speculative at this point, but future research could attempt to disentangle if and why incidental shame has the capacity to boost cooperation when it is the result of calculative decision-making (as in proselfs who are concerned with their cooperative reputation), or impede cooperation when it is the result of intuitive decision-making (as in cautious prosocials).

We believe the current study contributes to the literature of human social behavior in at least two ways. First and consistent with the literature on social emotions, we have shown for the first time that incidental feelings of shame can influence social behavior. According to the affect-as-information model, the affective state associated with shame is not an end in itself, but a means to an end, namely, to adjust the decision-making process so that future shame is avoided. As a heuristic, shame differs from guilt which elicits a desire to repair the damage done to other and provokes prosocial behavior as a remorse (Baumeister et al., 1994). If shame were to trigger remorse, we would also have observed an increase in cooperation in the simPD, as has previously been shown for guilt (Nelissen et al., 2007). Instead, shame appeared to trigger reputation concerns, at least for proselfs. The second contribution is that the action tendencies of shame appear to be context and value-dependent. Shame increased cooperative decision-making of proself individuals in situations where the intent of the decision was clearly visible. At the same time, it appears that shame may also have a general negative effect on cooperation of prosocial individuals, although this was not expected and requires further testing.

The context- and value- dependency of shame with respect to prosocial decisionmaking implies that the prosocial influence of shame may be very culturally sensitive. In our study, prosocials were not positively affected by shame because we postulated that shame 
was not informative in their utility function because the stakes of reputation losses are small compared to proselfs. Possibly, in cultures where honor is revered, and where shame is prominent when honors are broken, anticipated shame would likely exert a greater main effect, regardless of context and individual differences. Thus another interesting avenue for future research is to investigate how the incidental effect of shame affects cultures that excessively value their honor.

To conclude, incidental shame can infuse cooperative decision-making of proselfs when they cannot hide their greedy motives. However, shame does not change their intrinsic nature because it is used as a means to put the self-serving motive to work. Ironically, shame boosts cooperative behavior of proselfs by enforcing their concern for reputation and hence their self-centeredness.

\section{Acknowledgments:}

This study was supported by an NOI grant from the University of Antwerp (\#1044). We thank the following graduate students at the University of Antwerp for their help woth performing the experiment: Liesbeth Adriaenssens, Sandy Bogaert, Tine Buyl, Griet Emonds, Linda Mertens, Jesse Segers, Kim Sluyts, and Johanna Verstraeten. 


\section{References}

Au, W., \& Kwong, J. Y.Y. ( 2004). Measurement and effects of social value orientation in social dilemmas: A review. In R. Suleiman, D. Budescu, I. Fischer, \& D. Messick (Eds.), Contemporary Psychological Research on Social dilemmas (pp. 71-98). Cambridge:

Cambridge University Press.

Baumeister, R. F., Stillwell, A. M., \& Heatherton, T. F. (1994). Guilt: An interpersonal approach. Psychological Bulletin, 115, 243-267.

Bateson, M., Nettle, D., \& Roberts, G. (2006). Cues of being watched enhance cooperation in a real-world setting. Biology Letters, 2, 412-414.

Bogaert, S., Boone, C., \& Declerck, C. (2008). Social value orientation and cooperation in social dilemmas: A review and conceptual model. British Journal of Social Psychology, 47, 453-480.

Boone, C., Declerck, C. H., \& Kiyonari, T. (2010). Inducing cooperative behavior among proselfs versus prosocials: the moderating role of incentives and trust. Journal of Conflict Resolution, 54, 799-824.

Bowles, S., \& Gintis, H. (2002). Prosocial emotions. Paper presented at the Economy as a Complex Evolving System, III, Santa Fe, New Mexico. 
Brown, R., Gonzales, R., Zagefka, H., Manzi, J., \& Cehajic, S. (2008). Nuestra culpa:

Collective guilt and shame as predictors of reparation for historical wrongdoing. Journal of Personality and Social Psychology, 94, 75-90.

Cialdini, R., Darby, B. L., \& Vincent, J. E. (1973). Transgression and altruism: A case for hedonism. Journal of Experimental Psychology, 9, 502-516.

Clore, G. L. (1994). Why emotions are felt. In P. Ekman \& R. J. Davidson (Eds.), The Nature of Emotion: Fundamental Questions (pp. 103-111). New York: Oxford University Press.

Clore, G. L., Schwarz, N., \& Conway, M. (1994). Affective causes and consequences of social information processing. In R. S. Wyer \& T. K. Srull (Eds.), Handbook of Social Cognition (Vol. 1, pp. 323-417). Hillsdale, New Jersey: Erlbaum.

Darwin, C. [1872] (1998). The Expression of the Emotions in Man and Animal. New York: Oxford University Press.

De Cremer, D., \& Van Lange, P. A. M. (2001). Why prosocials exhibit greater cooperation than proselfs: The roles of social responsibility and reciprocity. European Journal of Personality, 15, S5-S18.

De Hooge, I. E., Breugelmans, S. M., \& Zeelenberg, M. (2008). Not so ugly after all: When shame acts as a commitment device. Journal of Personality and Social Psychology, 95, 933943. 
De Hooge, I. E., Zeelenberg, M, \& Breugelmans, S. M. (2007). Moral sentiments and cooperation: Differential influences of shame and guilt. Cognition and Emotion, 21, 10251045

Emonds, G., Declerck, C. H., Boone, C., Vandervliet, E., \& Parizel, P. (2010). Comparing the neural basis of strategic decision-making in people with different social preferences, an fMRI study. Journal of Neuroscience, Psychology, and Economics. In Press.

Forgas, J. P. (1995). Mood and judgment: The affect infusion model (AIM). Psychological Bulletin, 117, 39-66.

Frank, R. H. (1988). Passions within Reason. New York: Norton \& Company.

Frijda, N. H., Kuipers, P., \& Ter Schure, E. (1989). Relations among emotion appraisal and emotional action readiness. Journal of Personality and Social Psychology, 57, 212-228.

Gneezy, U., \& Rustichini, A. (2000). A fine is a price. Journal of Legal Studies, 29, 1-17.

Haidt, J. (2003). The moral emotions. In R. J. Davidson, K. R. Scherer, \& H. H. Goldsmith (Eds.), Handbook of Affective Sciences (pp. 852-870). Oxford: Oxford University Press.

Haley, K. J., \& Fessler, D. M. T. (2005). Nobody's watching? Subtle cues affect generosity in anonymous economic games. Evolution and Human Behavior, 26, 245-256. 
Haruno, M., \& Frith, C. D. (2010). Activity in the amygdala elicited by unfair divisions predicts social value orientation. Nature Neuroscience, 13, 160-161.

Ketelaar, T., \& Au W. T. (2003). The effects of feelings of guilt on the behavior of uncooperative individuals in repeated bargaining games: An affect as information interpretation of the role of emotion in social interaction. Cognition and Emotion, 17, 492453.

Kollock, P. (1998). Social dilemmas: The anatomy of cooperation. Annual Review of Sociology, 24, 183-214.

Lerner, J. S., \& Keltner, D. (2000). Beyond valence: Toward a model of emotion specific influences on judgment and choice. Cognition and Emotion, 14, 473-493.

Miettinen, T., \& Suetens, S. (2008). Communication and guilt in a prisoner's dilemma. Journal of Conflict Resolution, 52, 945-960.

Nelissen, R. M. A., Dijker, A. J. M., \& De Vries, N. K. (2007). How to turn a hawk into a dove and vice versa: Interactions between emotions and goals in a give some dilemma game. Journal of Experimental Social Psychology, 43, 280-286.

Pruitt, D. G., \& Kimmel, M. J. (1977). 20 years of experimental gaming - Critique, synthesis, and suggestions for the future. Annual Review of Psychology, 28, 363-392. 
Schwartz, N., \& Clore, G. L. (1983). Mood, misattribution, and judgments of well-being: Informative and directive functions of affective states. Journal of Personality and Social Psychology, 45, 513-523.

Simpson, B. (2004). Social values, subjective transformations, and cooperation in social dilemmas. Social Psychology Quarterly, 67, 385-395.

Simpson, B., \& Willer, R. (2008). Altruism and indirect reciprocity: The interaction of person and situation in prosocial behavior. Social Psychology Quarterly, 71, 37-52.

Slovic, P., Finuncane, M., Peters, E., \& MacGregor, D. G. (2004). Risk as analysis and risk as feelings: Some thoughts about affect, reason, and rationality. Risk Analysis, 24, 1-12.

Takahashi, H., Yahata, N., Koeda, M., Matsuda, T., Asai, K., \& Okubo, Y. (2004). Brain activation associated with evaluative processes of guilt and embarrassment: An fMRI study. Neuroimage, 23, 967-974.

Tangney, J. P., Stuewig, J., \& Mashek, D. J. (2007). Moral emotions and moral behavior. Annual Review of Psychology, 58, 435-372.

Van Lange, P. A. M. (1992). Confidence in expectations - A test of the triangle hypothesis. European Journal of Personality, 6, 371-379. 
Van Lange, P. A. M. (2000). Beyond self-interest: A set of propositions relevant to interpersonal orientations. In W. Stroebe \& M. Hewstone (Eds.), European Review of Social Psychology (Vol. 11, pp. 297-331). New York: Wiley.

Van Lange, P. A. M., Otten, W., De Bruin, E. M. N., \& Joireman, J. A. (1997). Development of prosocial, individualistic, and competitive orientations: Theory and preliminary evidence. Journal of Personality and Social Psychology, 73, 733-746.

Van Lange, P. A. M., \& Semin-Goossens, A. (1998). The boundaries of reciprocal cooperation. European Journal of Social Psychology, 28, 847-854.

Van Vugt, M., De Cremer, D., \& Janssen, D. P. (2007). Gender differences in cooperation and competition. The male warrior hypothesis. Psychological Science, 18, 19-23.

Wedekind, C., \& Milinski, M. (2000). Cooperation through imate scoring in humans. Nature, $288,850-852$.

Zinck, A. (2008). Self-referential emotions. Consciousness and Cognition, 17, 496-505. 